\title{
Article \\ Modeling of the Wind Potential in the Open Sea and Its Application to the Calculation of Energy
}

\author{
Manuel I. Bahamonde García ${ }^{1, *}{ }^{\mathbb{C}}$, José Macías Macías ${ }^{1}$, César Rodríguez González ${ }^{2} \mathbb{D}$, Salvador Pérez Litrán ${ }^{1} \mathbb{C}$ \\ and María R. Sánchez Herrera ${ }^{1}$ \\ 1 Department of Electric and Thermal Engineering, Design and Projects, University of Huelva, \\ 21007 Huelva, Spain; jose.macias@dfaie.uhu.es (J.M.M.); salvador@dfaie.uhu.es (S.P.L.); \\ reyes.sanchez@dfaie.uhu.es (M.R.S.H.) \\ 2 Department of Mining, Mechanical, Energy and Construction Engineering, University of Huelva, \\ 21007 Huelva, Spain; cesar@didp.uhu.es \\ * Correspondence: bahamonde@uhu.es
}

Citation: Bahamonde García, M.I.; Macías Macías, J.; Rodríguez González, C.; Litrán, S.P.; Sánchez Herrera, M.R. Modeling of the Wind Potential in the Open Sea and Its Application to the Calculation of Energy. Energies 2022, 15, 1157.

https://doi.org/10.3390/ en15031157

Academic Editors: Jose Ignacio Muñoz-Hernandez and Luis Baringo

Received: 9 December 2021

Accepted: 29 January 2022

Published: 4 February 2022

Publisher's Note: MDPI stays neutral with regard to jurisdictional claims in published maps and institutional affiliations.

Copyright: (C) 2022 by the authors. Licensee MDPI, Basel, Switzerland. This article is an open access article distributed under the terms and conditions of the Creative Commons Attribution (CC BY) license (https:// creativecommons.org/licenses/by/ $4.0 /)$.

\begin{abstract}
A reliable estimate of the wind potential in the marine atmospheric boundary layer (MABL) is of great importance to justify the energetic viability of new offshore wind farms. The purpose of the study is to provide an additional tool for the prediction of the energy that a wind turbine would produces in the open sea from the usual way of measurements at sea, that is, when they are carried out with measuring masts, where the meteorological data are obtained at levels much lower than those of a wind turbine hub. For this, the variation in the wind speed with the height in the MABL is determined, based on the Monin-Obukhov similarity theory, according to the boundary conditions of the air-sea interface, where the input data for the Validation of the results are extracted from the German FINO 3 research platform during the years 2016, 2017, and 2018. It is applied to the production of electrical energy from a 6.0 MW commercial wind turbine, with the hub at $100 \mathrm{~m}$ above the sea surface. As a more prominent result, the deviations from the proposed method do not exceed $2.5 \%$ in the energy calculation.
\end{abstract}

Keywords: wind energy; similarity theory; atmospheric stability; Richardson's number; sea surface roughness; offshore wind turbines; energy production

\section{Introduction}

Offshore wind energy, with a total installed capacity at the end of 2020 of 35,300 MW [1], has had a great expansion in recent years. In this field, worldwide, there are large unexploited marine extensions with moderate to strong winds, which require a reliable method of predicting wind potential, with the aim of studying the electrical energy that would be produced by the offshore wind farms to be installed in the future.

Although the wind of the atmospheric surface layer is usually simplified considering that it is a two-dimensional vector magnitude defined by the speed and the direction [2]. The modeling of the variation in the wind speed with the height in short periods of time presents serious difficulties as there is not always continuity in growth, sometimes it even decreases with height [3]. On the other hand, the same does not happen with the direction of the wind, whose value remains practically constant at different levels of the surface layer.

Currently, the installation and maintenance costs of offshore wind farms are higher than their onshore counterparts, and this difference can be compensated for by the better characteristics of the wind at sea. However, a deeper knowledge is necessary to determine the long-term wind potential that can be translated into new decision tools. Along this line, it must be considered that the surface layers of the land and the sea are different, both in terms of quantity of movement exchanges, as well as in heat and moisture fluxes [4], and, also because the sea surface presents a constant change having a continuous length of aerodynamic roughness due to swell [5]. 
In estimating the wind resource, it has been common for marine conditions to adopt a neutral atmospheric stratification and a reduced roughness of the sea surface, which is sometimes taken as practically smooth. That is why offshore wind energy requires a better understanding of MABL, such as atmospheric stability, roughness of the sea surface, turbulence, heat exchange, and the amount of movement that occurs in the air [6].

\subsection{Wind Profile in the $M A B L$}

The power law (1), from the IEC 61400-3 [7] standard, where the wind speed, $U(z)$, is obtained as a function of height, $z$, above mean sea level, from the mean input wind value, $U_{h u b}$, for hub height, $z_{h u b}$, with a constant value of the exponent for marine conditions equal to 0.14 , does not take into account atmospheric stratification or roughness of the sea surface, giving a higher value of the wind speed at the height of the hub of the wind turbines [8], and being adequate for the study of their design conditions.

$$
U(z)=U_{h u b}\left(z / z_{h u b}\right)^{\alpha}
$$

On the other hand, the Monin-Obukhov (M-O) [9] similarity theory contemplates the MABL boundary conditions. Thus, under conditions of neutral atmospheric stratification, in relation to the momentum, Equation (2) represents a logarithmic profile of the variation in the wind speed with the height.

$$
U(z)=u_{*} / k \ln \left(z / z_{0}\right)
$$

where $k$ is the von Kármán constant, which usually takes a value of $0.4, z_{0}$ is the aerodynamic roughness length and $u_{*}$ is the friction velocity, which is defined by the following expression:

$$
u_{*}^{2}=\left|\frac{\tau}{\rho}\right|
$$

where $\tau$ is the surface tension, which acts parallel on the surface of the sea, $\rho$ is the air density and $u_{*}^{2}$ is the kinematic tension.

Moreover, based on this theory, the diabatic profile of the wind is given by:

$$
U(z)=u_{*} / k\left[\ln \left(z / z_{0}\right)+\Psi_{M}(z / L)\right]
$$

where $L$ is the Obukhov length [10], expressed as:

$$
L=-\frac{u_{*}^{3}}{k \frac{g}{\bar{\theta}_{v}} F_{H s}}
$$

where $g / \bar{\theta}_{v}$ is the buoyancy in $\mathrm{m} / \mathrm{s}^{2} \mathrm{~K}$, and the heat kinematic flux, $F_{H s}$, in $\mathrm{K} \mathrm{m} / \mathrm{s}$ will be changing during the daily cycle and we will use the approximate expression [11]:

$$
F_{H s}=C_{H} U\left(T_{s}-T_{a}\right)
$$

where $T_{a}$ is the air temperature, $T_{s}$ is the water temperature on the sea surface, and $C_{H}$ is the coefficient of main transfer of sensible heat. The value of said dimensionless coefficient ranges between 0.001 and 0.005 for neutral conditions, takes a value of 0.006 for unstable atmosphere, and varies between 0.0009 and 0.000001 for stable conditions [12].

The atmospheric stratification processes in the surface layer are given by the empirical function, $\Psi_{M}(z / L)$ [3]; thus, for neutral stratification, $z / L=0$, the function $\Psi_{M}(z / L)$ is zero in Equation (4). Instead, for unstable atmosphere, $z / L<0$, the function $\Psi_{M}(z / L)$ is represented by the Paulson equation [13]:

$$
\Psi_{M U}(z / L)=-2 \ln \left(\frac{1+x}{2}\right)-\ln \left(\frac{1+x^{2}}{2}\right)+2 \tan ^{-1}(x)-\pi / 2
$$


where $x=\left[1-\left(\frac{15 z}{L}\right)\right]^{1 / 4}$.

For stable stratification, $z / L>0$, and the function $\Psi_{M}(z / L)$ is represented by the Businger-Dyer equation $[14,15]$ :

$$
\Psi_{M S}(z / L)=\frac{4.7 z}{L}
$$

Graphically, the wind speed profile with neutral atmospheric stratification, Equation (2), appears as a straight line when represented with a semi-logarithmic scale. Whereas, according to Equation (4), for the non-neutral cases, the profile of the wind speed with the height deviates slightly from the logarithmic one, in such a way that under conditions of stable atmospheric stratification the wind profile is concave downward, while under conditions of unstable atmospheric stratification it is concave upward. That is, with respect to neutral stratification, the wind speed increases in the first case (stability) and decreases in the second case (instability).

Graphically, in Figure 1a, the wind speed profile with neutral atmospheric stratification, Equation (2), appears as a straight line when it is represented with a semi-logarithmic scale. Whereas, according to Equation (4), for the non-neutral cases, the profile of the wind speed with the height deviates slightly from the logarithmic one, in such a way that under conditions of stable atmospheric stratification the wind profile is concave towards below, while under conditions of unstable atmospheric stratification, it is concave upwards. That is, with respect to neutral stratification, the wind speed increases in the first case (stability) and decreases in the second case (instability). Likewise, Figure $1 \mathrm{~b}$ represents the previous equations of the similarity theory and the power law (1), which presents a profile at higher elevations, from the measurement elevation, with less slope than the logarithmic equation under stratification conditions neutral, giving higher values of wind speeds for the same height.

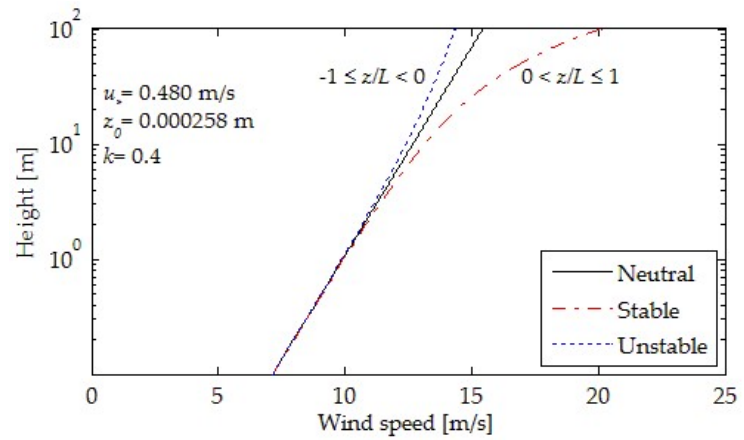

(a)

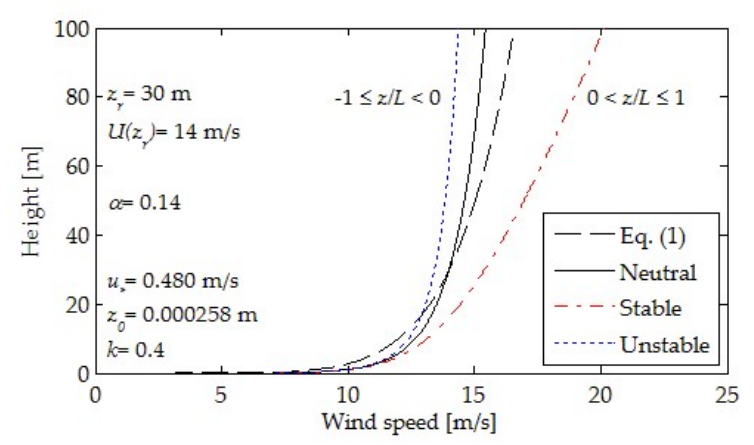

(b)

Figure 1. Variation in wind speed with height according to atmospheric stratification.

\subsection{Aerodynamic Roughness Length}

The variation in wind speed with height through a logarithmic profile under neutral conditions and the general shape of the similarity functions under non-neutral conditions have been confirmed in observations on the water surface [3,16]. From these measurements, the transfer coefficients and the aerodynamic roughness length can be determined, $z_{0}$, which is defined as the height above a surface where the wind speed cancels out.

At sea, the continuous movement of the surface determines a variable roughness length, which influences the logarithmic wind profile of the similarity theory. Thus, with very light winds, less than $4 \mathrm{~m} / \mathrm{s}$, the sea surface approaches a smooth aerodynamic surface, independent of the geometry of the rough element [17] and is given by the equation:

$$
z_{0}=\frac{0.11 v}{u_{*}}
$$


where $v=1.461 \cdot 10^{-5} \mathrm{~m}^{2} / \mathrm{s}$ is the kinematic molecular viscosity, as parameter of air at sea level for a standard atmosphere [3].

With wind speeds between 4 and $50 \mathrm{~m} / \mathrm{s}$, Equation (10) is applicable, called Charnock's relationship [18], where the roughness length increases when the kinematic stress increases.

$$
z_{0}=\frac{\alpha_{c} u_{*}^{2}}{g}
$$

where $\alpha_{\mathcal{c}}$, it is a constant, called the Charnock parameter, which is usually quoted between 0.01 and 0.04 [19], and which takes from this range low values for open sea and high values for sites near shore.

Thus, due to said behavior and the data available at the marine sites, a simplification in the logarithmic profile of the wind speed in the MABL, considering a constant roughness length and a neutral atmospheric stratification in all marine sites, is not an approach in line with the experimental evidence [20].

\subsection{Literature Review, Novelty, and Objectives of This Paper}

The accumulated experience in the onshore wind industry was collected by the International Electrotechnical Commission (IEC) in the IEC 61400-1 standard [21] and extended for marine conditions in the IEC 61400-3 standard [7]. Likewise, certifying entities such as Germanischer Lloyd (GL) and Det Norske Veritas (DNV) applied their codes and standards of the offshore oil and gas industries to the offshore wind industry. Thus, in relation to the wind potential, IEC [7] and GL [22] apply the power law (1) in the model of the normal wind profile (NWP), where a neutral atmospheric stratification and a constant roughness of the sea surface are considered. On the other hand, DNV [23] indicates that the variation in the wind speed with height under normal conditions adopts a logarithmic profile given by Equation (2) with neutral stratification and with a variable value of the roughness length given by the Charnock equation [18]; it also expresses the use of the power law (1) as a possible alternative.

Based on these considerations, the use of the power law (1) and logarithmic Equation (2) do not fully describe the wind potential in a marine location at any latitude, so it can give deviations in the energy calculation for deciding on the energy viability of an offshore wind project. In this sense, Lange et al. [24] indicate that the estimates of the power output of wind turbines improve significantly if atmospheric stability is taken into account. Kalvig et al. [6] also indicate that there is a gap between the best knowledge of MABL and its practical applications, requiring a review of the influence on energy production in offshore wind turbines if the stability of the atmosphere is taken into account along with the interaction of the wind on the surface of the sea.

Therefore, the novelty of the present study of wind potential considers the use of the extended logarithmic Equation (4) for all cases of atmospheric stability, neutral and non-neutral, which occur in the MABL, with a continuous variation in ten-minute intervals. The logarithmic factor of this equation includes the aerodynamic roughness length, which is related to a continuous variation of the swell, which has a minimal effect on the wind speed profile in the open sea [25].

The objectives of the paper are, on the one hand, the study of the wind potential by means of the M-O extended equation based on data from a ten-minute series, and, on the other, its application to the calculation of the energy of a commercial marine wind turbine.

The characterization of the marine site in each year of the study includes:

- A quantitative analysis of the atmospheric stratification, to ascertain the boundary conditions and assess their influence on the wind speed.

- The calculation of the friction velocity and the aerodynamic roughness length as a function of the wind speed measured at the lower level. 
The deviations in the model with respect to the real data were obtained by means of the relation of the measured and predicted wind speeds to the height of the hub of a commercial wind turbine.

Finally, as an application of the proposed model, the validation of the results is summarized in the estimation of the energy that said wind turbine would produce in the open sea, through its operating parameters.

\section{Materials and Methods}

The study developed in this article is outlined in Figure 2. The input data were obtained from the German research platform FINO 3 [26] in a ten-minute series during the years 2016, 2017, and 2018, these are the temperature of the sea surface and meteorological data at $30 \mathrm{~m}$ above sea level, and the characteristic curves of the Siemens-Gamesa SWT6.0 MW-154 wind turbine with the hub at $100 \mathrm{~m}$. For data processing, several computer tools were developed in order to model the variation in the wind speed at the height of the hub of the wind turbine.

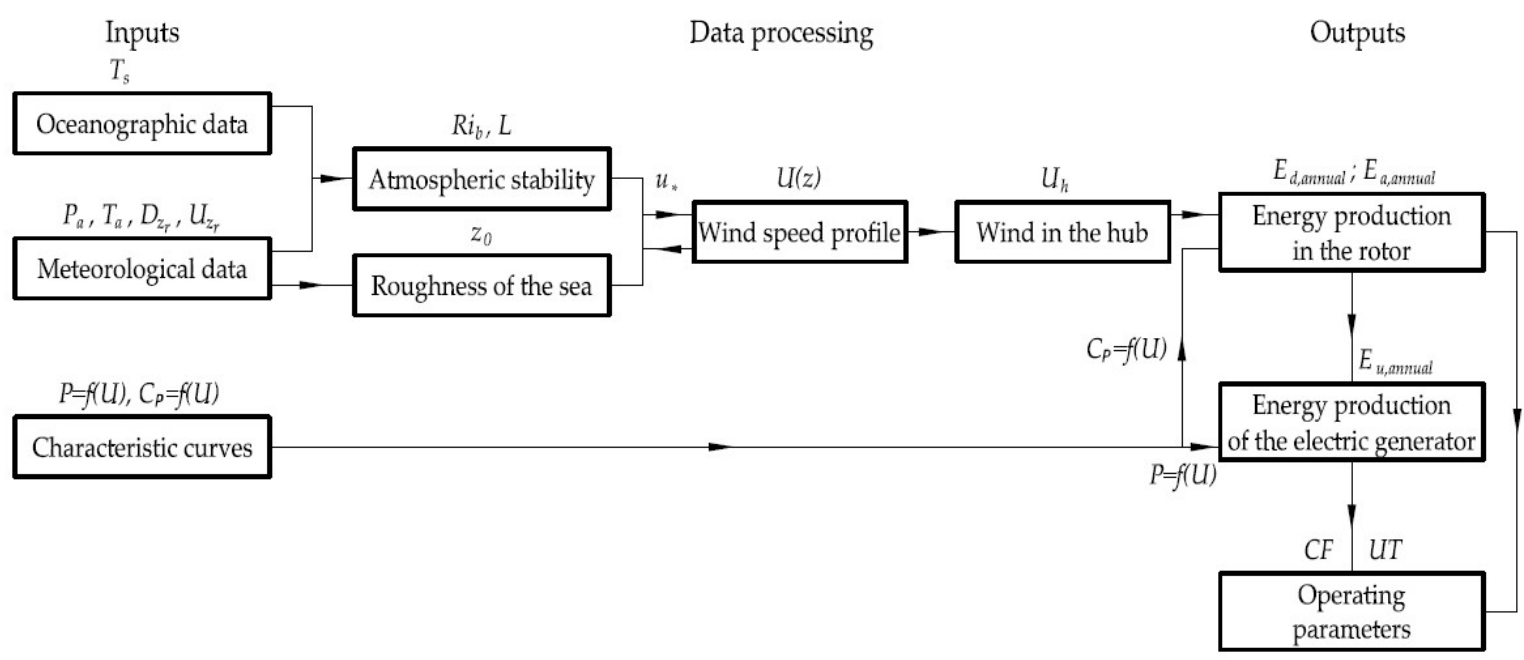

Figure 2. Scheme of the applied methodology, based on [12].

Figure 3 shows the geographical location of the FINO research platforms. Specifically, FINO 3, with coordinates: $55^{\circ} 11.7^{\prime} \mathrm{N}, 007^{\circ} 9.5^{\prime} \mathrm{E}$, is located about 45 nautical miles west of Sylt, off the coast of Schleswig-Holstein, in the North Sea.

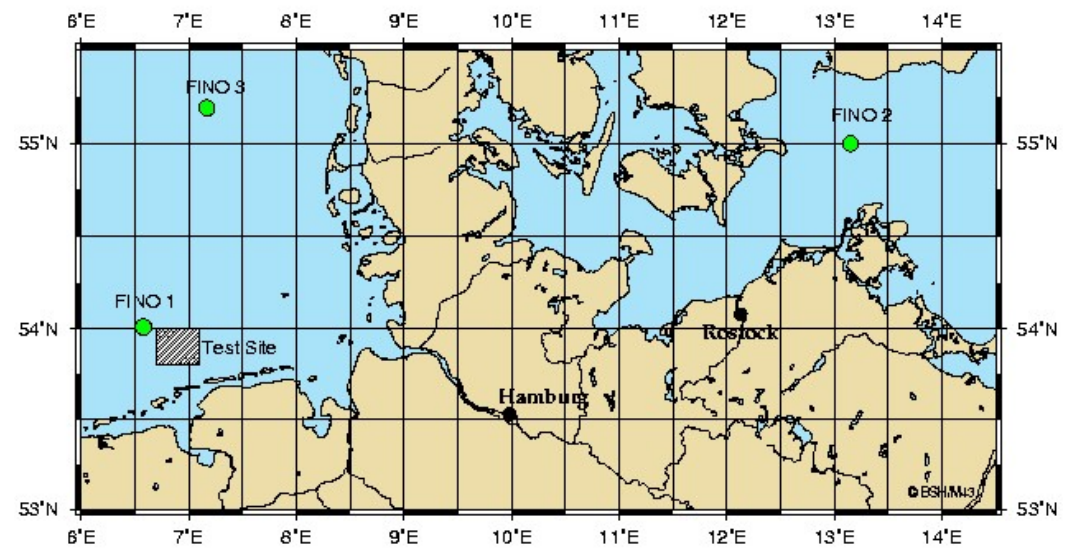

Figure 3. Location of FINO research platforms.(Bundesamt für Seeschifffahrt und Hydrographie, Government of Germany). 


\subsection{Initial Parameters}

The dimensionless Richardson number, $R i$, represents the balance between the thermal and mechanical effects in the generation of the turbulent state of the lower layers of the atmosphere. In particular, the atmospheric stability conditions were determined by the bulk Richardson number, $R i_{b}$, given by the Equation(11):

$$
R i_{b}=\frac{g z\left(T_{a}-T_{s}\right)}{\left(273.15+T_{a}\right) U^{2}}
$$

where $g$ is the acceleration due to gravity and $U$ is the wind speed measured at a height $z$. The choice of this method is due to the fact that it requires few measuring instruments to characterize the atmospheric stability in the high seas, with good results $[27,28]$.

The grouping of data obtained by the bulk Richardson number has been performed in a range between -0.02 and +0.02 for neutral atmosphere, for values less than -0.02 unstable atmosphere, and for values greater than +0.02 atmosphere stable [29].

The calculation of the friction velocity, $u_{*}$, was carried out by means of the numerical method of iteration of the fixed point, as follows:

If $U<4 \mathrm{~m} / \mathrm{s}$, Equation (9) is substituted in Equation (4):

$$
u_{*}=\frac{U k}{\ln \left(\frac{z u_{*}}{0.11 v}\right)+\Psi_{M}\left(\frac{z}{L}\right)}
$$

If $4 \leq U \leq 50 \mathrm{~m} / \mathrm{s}$, Equation (10) is substituted in Equation (4):

$$
u_{*}=\frac{U k}{\ln \left(\frac{z g}{\alpha_{c} u_{*}^{2}}\right)+\Psi_{M}\left(\frac{z}{L}\right)}
$$

with the Charnock constant for open sea, $\alpha_{c}=0.011$. Likewise, in Equations (12) and (13) the stability function $\Psi_{M}(z / L)$ is zero for a neutral atmosphere, or it takes the value given by Equation (7) for an unstable atmosphere or the value given by Equation (8) for a stable atmosphere.

Known the friction velocity, the aerodynamic roughness length is obtained by Equations (9) and (10). The Obukhov length, $L$, is calculated below in each ten-minute interval using Equation (5), where the average virtual potential temperature, $\bar{\theta}_{v}$, for unsaturated air, with mixing ratio $r$, is given by the following equation [3]:

$$
\bar{\theta}_{v}=\theta(1+0.64 r)
$$

with $r=20 \mathrm{~g} / \mathrm{kg}$, and the potential temperature, $\theta$, by the following expression:

$$
\theta=T_{a}\left(P_{o} / P_{a}\right)^{0.286}
$$

where $P_{a}$ is the air pressure and $P_{o}$ the reference pressure, which will be taken as $100 \mathrm{kPa}$.

\subsection{Wind Speed at Hub Height}

In the last stage of modeling, known $u_{*}, z_{0}$ and $L$, the wind speed is determined, $U_{h}$, at the new height, $h$, of the surface boundary layer, according to the general expression (4), for the following cases:

- $\quad$ Neutral atmospheric stratification, $h / L=0$, where Equation (4) reduces to Equation (2).

- Unstable atmospheric stratification, $h / L<0$, substituting Equation (7) in Equation (4), it results:

$$
U_{h}=u_{*} / k\left[\ln \left(h / z_{0}\right)-2 \ln \left(\frac{1+x}{2}\right)-\ln \left(\frac{1+x^{2}}{2}\right)+2 \tan ^{-1}(x)-\pi / 2\right]
$$

where $x=\left[1-\left(\frac{15 h}{L}\right)\right]^{1 / 4}$. 
- $\quad$ Stable atmospheric stratification, $h / L>0$, substituting Equation (8) in Equation (4), we obtain:

$$
U_{h}=u_{*} / k\left[\ln \left(h / z_{0}\right)+\frac{4.7 h}{L}\right]
$$

\subsection{Operating Parameters}

The action of the wind on the rotor of a wind turbine during an annual period produces the available energy, $E_{d, a n n u a l}$, expressed by discrete sums by the equation:

$$
E_{d, \text { annual }}=\sum_{i} T_{i} \dot{W}_{i}
$$

being $T_{i}$ the time of occurrence of each interval of the wind speed and $\dot{W}_{i}$ the power of the incident wind on the turbine rotor.

Likewise, of the energy available in an annual period, only the energy used is effective, $E_{a, \text { annual }}$, which is given by the equation:

$$
E_{a, \text { annual }}=\sum_{i} C_{P, i} T_{i} \dot{W}_{i}
$$

where $C_{P, i}$ is the rotor power coefficient of the wind turbine for each wind speed interval. A part of the energy used by the rotor is converted into drive energy, which transmits the motor torque to the electrical machine.

In the end, the conversion of the energy in the electric generator produces the useful energy, $E_{u, \text { annual }}$, which is given by discrete sums by the equation:

$$
E_{u, \text { annual }}=\sum_{i} T_{i} P_{i}
$$

where $P_{i}$ is the value of the power, extracted from the power curve of the selected wind turbine for each incident wind speed interval in a year. The summary of the energy calculations of a wind turbine is determined by the following operating parameters [30]:

- $\quad$ Capacity Factor $(C F)$ is the ratio between the useful energy, $E_{u, \text { annual }}$, produced by a wind turbine in a period of a year, $T$, and the energy that would have been produced if during this period it had been operating continuously at its rated power, $P_{n}$, which can be expressed by the following equation:

$$
C F=\frac{E_{u, \text { annual }}}{P_{n} \cdot T}
$$

- $\quad$ Usage Time (UT) is the number of hours that a wind turbine would have to operate at full load to produce the same energy in a year that would be obtained during its actual operation. It is given by the equation:

$$
U T=\frac{E_{u, \text { annual }}}{P_{n}}=8760 \cdot C F(\text { hours } / \text { year })
$$

We will use these parameters to carry out a comparative study of the energy that the selected wind turbine would produce at the site where the data are measured. Finally, the results obtained with the data measured on the FINO 3 research platform at the same elevation as the wind turbine are validated, that is, at $100 \mathrm{~m}$ above sea level. 


\section{Results}

\subsection{Atmospheric Stability}

Since the wind energy depends on the type of atmospheric stratification in a site, the modeling of the wind potential in the open sea begins by determining it, through the bulk Richardson number, $R i_{b}$, given by Equation (11).

Thus, from ten-minute data, such as air and sea surface temperatures and the wind speed at a height of $30 \mathrm{~m}$ above sea level, the corresponding dimensionless values were obtained. The grouping of these in a band around zero, between -0.02 and +0.02 , identifies the quasi-neutral stratification, which we will also call neutral. For dimensionless values lower than -0.02 , it will generically be called unstable atmospheric stratification. For dimensionless values higher than +0.02 it will be called, in general, stable atmospheric stratification.

The results obtained according to the bulk Richardson number are grouped in Table 1 with the objective of knowing the atmospheric stratification in each year of study at the site of the FINO 3 platform. The efficacy data is the relationship between valid data and total data in a year. Most of the cases represent quasi-neutral and unstable atmospheric stratifications, with the lowest number of cases being stable stratification. Even though the valid data measured in each year are different, it can be observed that the types of atmospheric stability remain within a certain range of percentage values, which characterizes, together with the direction and speed of the wind, the wind potential of the marine site.

Table 1. Atmospheric stratification at the site of FINO 3 platform.

\begin{tabular}{ccccccccc}
\hline \multirow{2}{*}{ Year } & Efficacy & \multicolumn{2}{c}{ Near-Neutral (N) } & \multicolumn{2}{c}{ Unstable (U) } & \multicolumn{2}{c}{ Stable (S) } & \multicolumn{2}{c}{ Total } \\
& Data & No. & \% & No. & \% & No. & No. \\
\hline 2016 & 0.823 & 20,085 & 46.31 & 20,607 & 47.51 & 2680 & 6.18 & 43,372 \\
2017 & 0.881 & 23,965 & 51.77 & 19,603 & 42.35 & 2722 & 5.88 & 46,290 \\
2018 & 0.763 & 17,397 & 43.36 & 17,019 & 42.42 & 5706 & 14.22 & 40,122 \\
\hline
\end{tabular}

The ten-minute values obtained are represented in Figures $4 \mathrm{a}$, 5a and $6 \mathrm{a}$ as dispersion graphs of the bulk Richardson number, $R i_{b}$, as a function of the wind speed measured at $30 \mathrm{~m}$ in the years 2016, 2017, and 2018. In a narrow band between -0.02 and 0.02 there are cases of neutral stratification for the entire range of wind speeds up to $25 \mathrm{~m} / \mathrm{s}$. From the horizontal by 0.02 upwards there are all the stable cases that, depending on the proximity to said line, can be: slightly stable, stable, and very stable, and from the horizontal by -0.02 downwards all the unstable cases, here, also depending on the proximity to said line, they can be: slightly unstable, unstable, and very unstable [31,32].

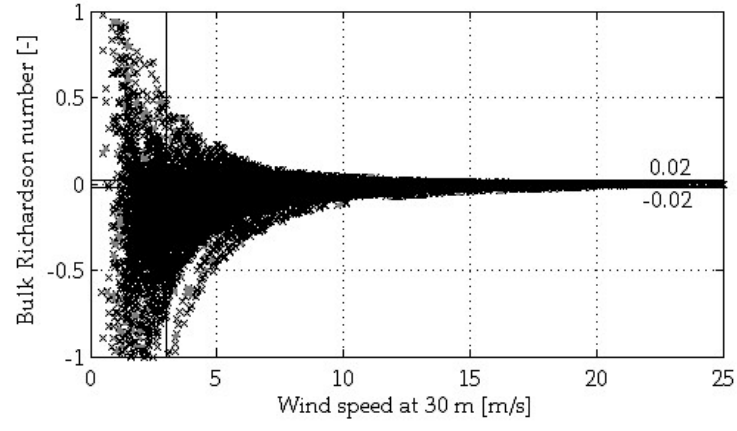

(a)

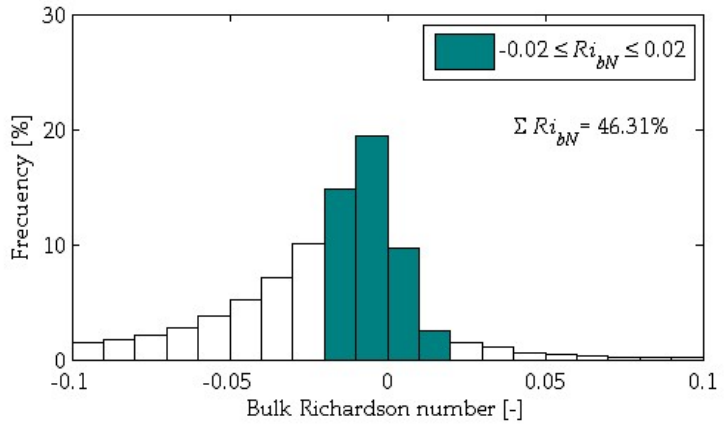

(b)

Figure 4. Graphs relating to atmospheric stability in 2016. 


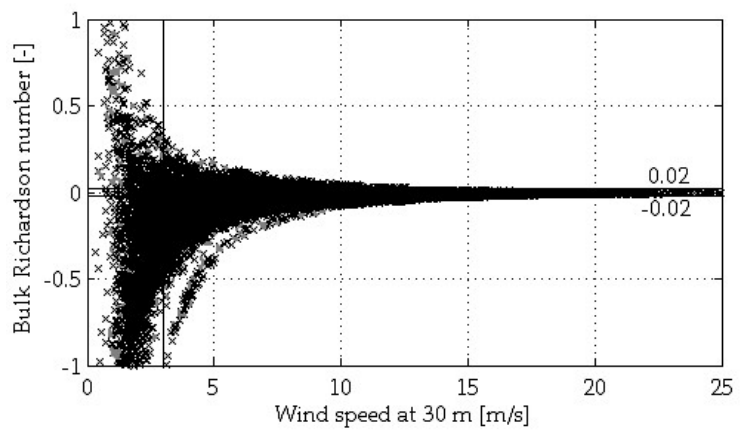

(a)

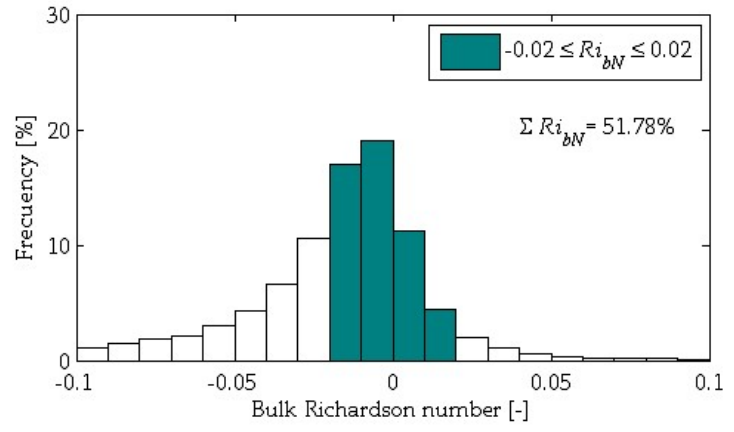

(b)

Figure 5. Graphs relating to atmospheric stability in 2017.

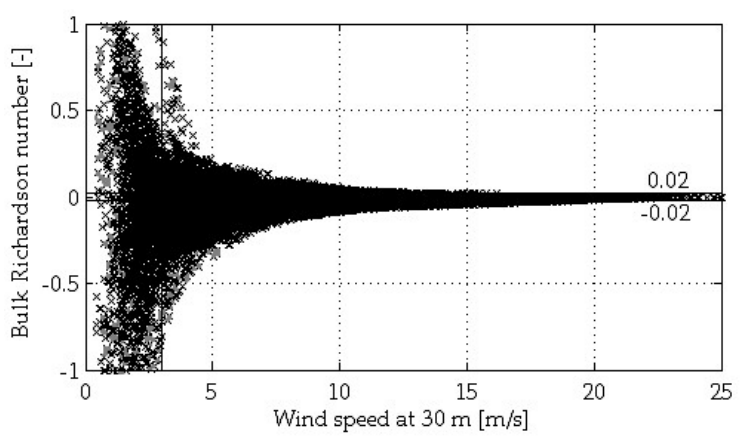

(a)

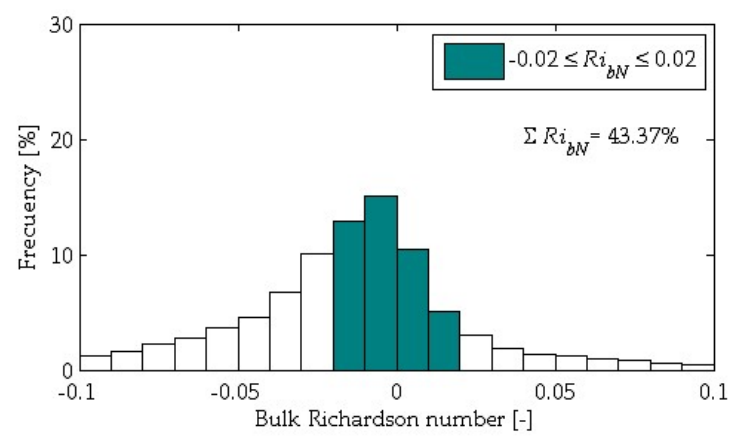

(b)

Figure 6. Graphs relating to atmospheric stability in 2018.

The reason for this behavior is due to the balance between the thermal effects (buoyancy force) and the mechanical effects (wind shear force) expressed in Equation (11), where the absolute value of depends mainly on the wind speed and its sign of the temperature difference [29]. If buoyancy is dominant, positive (stable atmosphere) or negative (unstable atmosphere), the Richardson bulk number is above 0.02 or below -0.02 , respectively. On the other hand, if the shear force of the wind is dominant, the value of the Richardson bulk number is in the range between 0.02 and -0.02 .

Likewise, Figures $4 b, 5 b$ and $6 b$ represent the frequencies of the values obtained according to the bulk Richardson number in the years 2016, 2017, and 2018, respectively. The quasi-neutral data, drawn with a filled bar, add up to a total of $46.31 \%, 51.78 \%$, and $43.37 \%$ in each of the related years, the rest of the data being drawn with unfilled bars, slightly unstable towards the negative part, and slightly stable towards the positive part.

Table 2 shows the distribution of the atmospheric stratification data at the FINO 3 site in the operating range, $\mathrm{R}$, of the selected wind turbine. Thus, discarding the values for wind speeds below $3 \mathrm{~m} / \mathrm{s}$, neutral stratification is predominant and intensifies with respect to the total data, it is closely followed by unstable stratification and stable stratification is very far behind.

Table 2. Atmospheric stratification at the site of FINO 3 for the operation range, $\mathrm{R}$, of the selected wind turbine.

\begin{tabular}{|c|c|c|c|c|c|c|c|c|}
\hline \multirow{2}{*}{ Year } & \multicolumn{2}{|c|}{ Near-Neutral $R\left(\mathbf{N}_{\mathbf{R}}\right)$} & \multicolumn{2}{|c|}{ Unstable $R\left(U_{R}\right)$} & \multicolumn{2}{|c|}{ Stable R $\left(S_{R}\right)$} & \multirow{2}{*}{$\begin{array}{c}\text { Total R } \\
\text { No. }\end{array}$} & \multirow{2}{*}{$\begin{array}{l}\text { Total } \\
\text { No. }\end{array}$} \\
\hline & No. & $\%$ & No. & $\%$ & No. & $\%$ & & \\
\hline 2016 & 19,979 & 49.24 & 18,454 & 45.48 & 2145 & 5.29 & 40,578 & 43,372 \\
\hline 2017 & 23,890 & 55.22 & 17,112 & 39.55 & 2262 & 5.23 & 43,264 & 46,290 \\
\hline 2018 & 17,303 & 45.51 & 16,072 & 42.28 & 4642 & 12.21 & 38,017 & 40,122 \\
\hline
\end{tabular}




\subsection{Friction Velocity}

Friction velocity, $u_{*}$, scatter diagrams are shown in Figures 7-9, as a function of wind speed measured at $30 \mathrm{~m}$ above sea level. For light winds, less than $4 \mathrm{~m} / \mathrm{s}$, Equation (12) was applied and for winds between 4 and $25 \mathrm{~m} / \mathrm{s}$, Equation (13) was used. Typical friction velocity values range from $0 \mathrm{~m} / \mathrm{s}$ for calm to $1 \mathrm{~m} / \mathrm{s}$ for strong winds $[3,16]$.

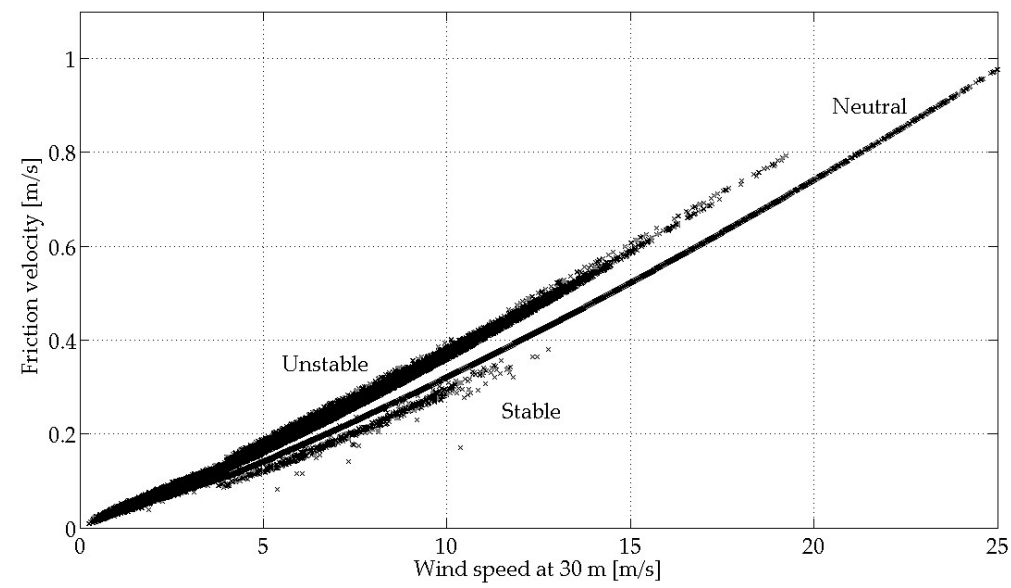

Figure 7. Friction velocity as a function of wind speed in 2016.

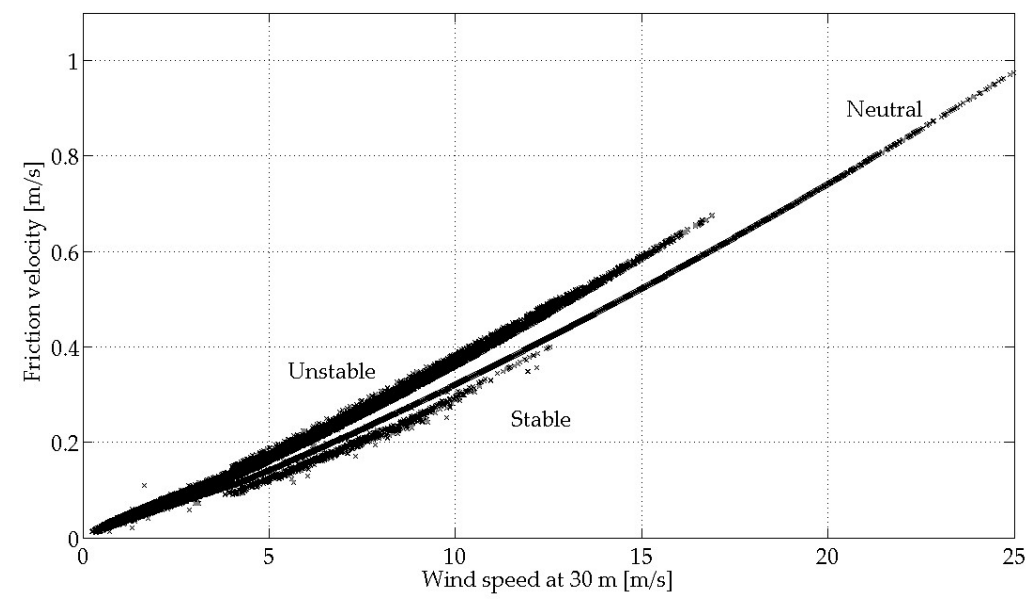

Figure 8. Friction velocity as a function of wind speed in 2017.

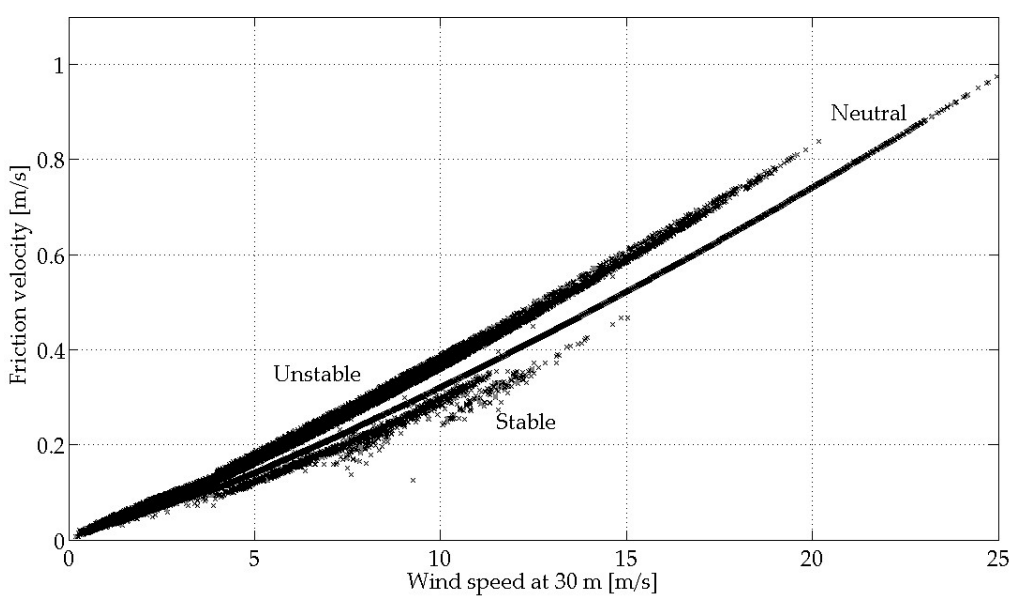

Figure 9. Friction velocity as a function of wind speed in 2018. 
As can be seen in the first part of the figures, in the region of light winds, the friction velocity is less than $0.2 \mathrm{~m} / \mathrm{s}$ and the atmospheric stratification zones are grouped. In the following region, the force of the wind on the sea surface, which originates from the waves, is translated into the friction velocity, which does not exceed $1 \mathrm{~m} / \mathrm{s}$ for $25 \mathrm{~m} / \mathrm{s}$; in addition, the three regions are differentiated according to the atmospheric stratification, the values for neutral stratification appear highly concentrated and are given for all surface wind speeds over the sea.

In general, the friction speed increases when the wind speed increases but at a different rate depending on the behavior of the sea surface in the limit of $4 \mathrm{~m} / \mathrm{s}$, as a smooth or rough surface, and atmospheric stratification. Thus, for wind speeds lower than $4 \mathrm{~m} / \mathrm{s}$, the friction speed growth slope is less than for wind speeds equal to, or greater than, $4 \mathrm{~m} / \mathrm{s}$; in addition, in this range, the function $\Psi_{M}(z / L)$ of Equation (4) also it has its effects, distinguishing the three stratification zones.

\subsection{Aerodynamic Roughness Length}

Figures 10-12 show the scatter diagrams of the roughness length, by application of Equations (9) and (10), as a function of the wind speed measured at $30 \mathrm{~m}$ above sea level, distributed according to atmospheric stability. Here too, for winds of $25 \mathrm{~m} / \mathrm{s}$, the values of the roughness length of the sea surface are very low, that is, they slightly exceed $1 \mathrm{~mm}$.

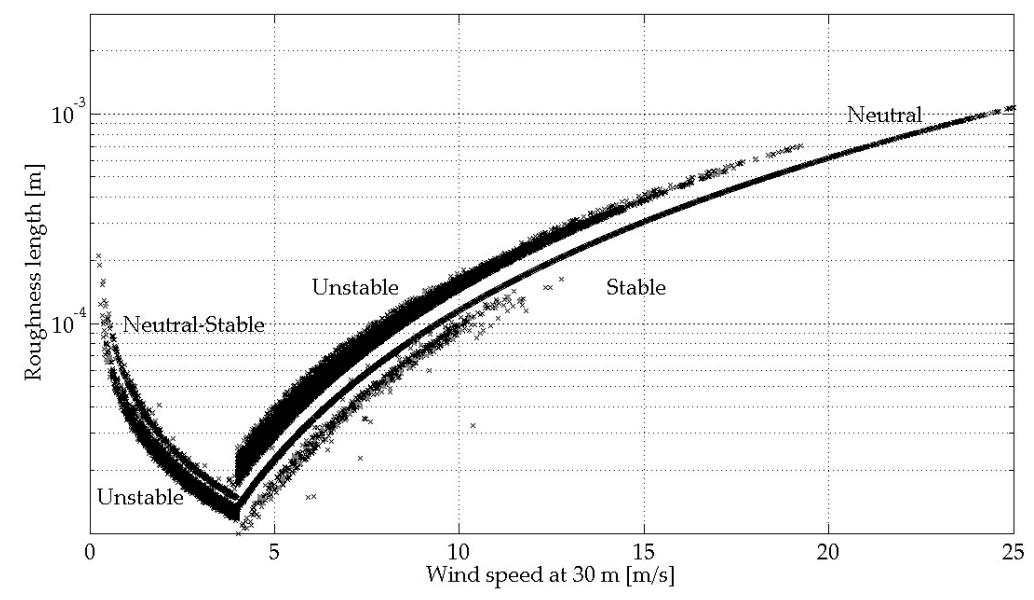

Figure 10. Aerodynamic roughness length in 2016.

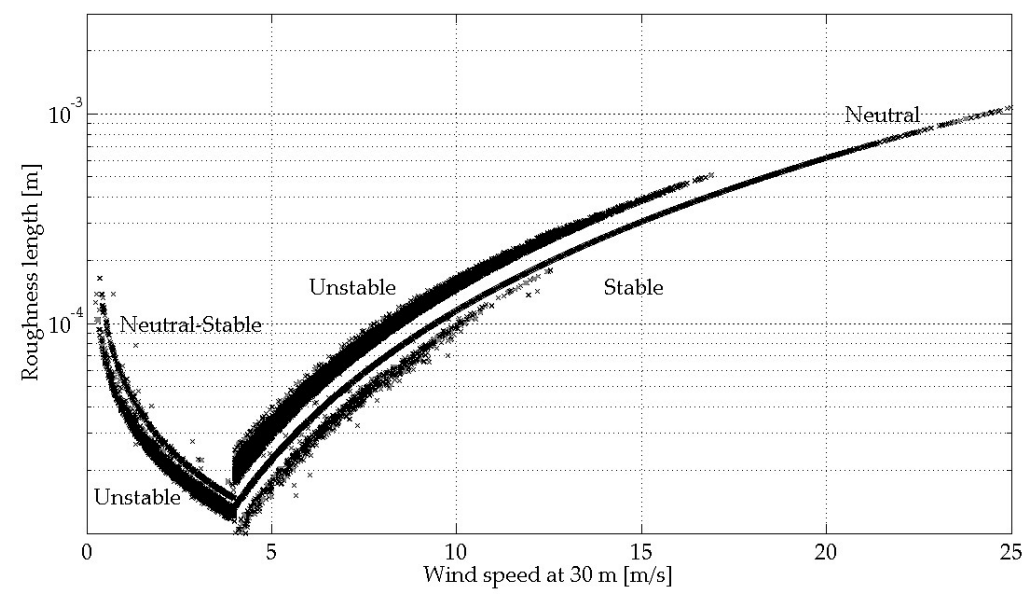

Figure 11. Aerodynamic roughness length in 2017. 


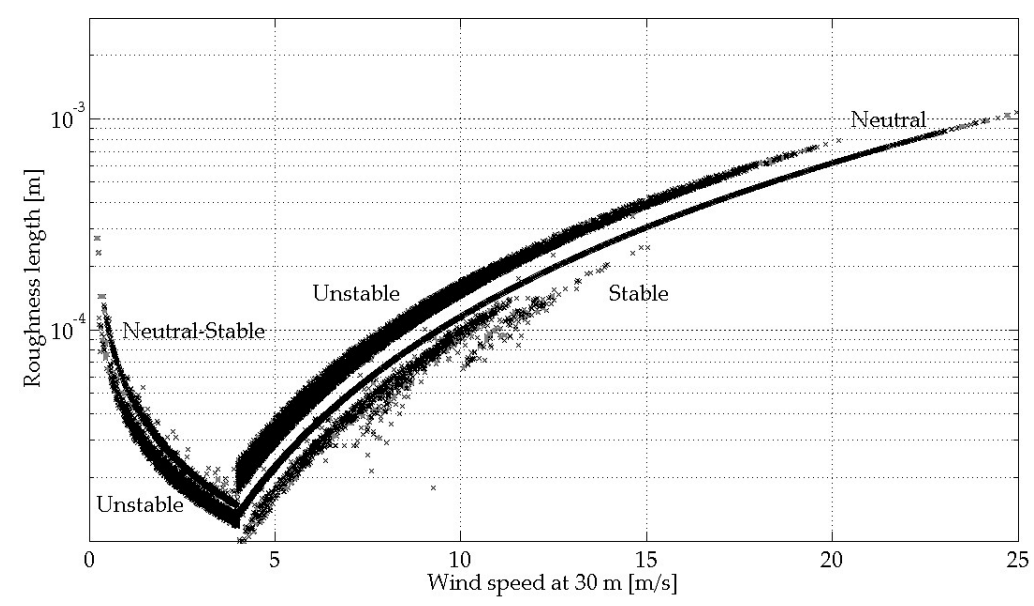

Figure 12. Aerodynamic roughness length in 2018.

In the graphs of Figures 10-12, the same trend is observed in the limit of $4 \mathrm{~m} / \mathrm{s}$; thus, for light winds, the sea surface behaves as a smooth surface, indicated by Equation (9), with a roughness length value close to zero and two regions atmospheric stratification: neutralstable and unstable. On the other hand, for winds between 4 and $25 \mathrm{~m} / \mathrm{s}$, Equation (10) has been applied and three clearly differentiated regions are represented, with a neutral atmosphere, the data obtained are concentrated in a very narrow band; on the other hand, for unstable and stable conditions the regions increase, being more compact with unstable stratification and more dispersed with stable stratification. In addition, in these figures, it can be observed that when the type of stability is neutral, the entire range of wind speeds occurs, that is, up to $25 \mathrm{~m} / \mathrm{s}$ and higher than this. Instead, when the atmospheric stratification is unstable, the wind speed does not exceed $20 \mathrm{~m} / \mathrm{s}$, its frequent values being up to $15 \mathrm{~m} / \mathrm{s}$, and when it is stable, it does not exceed $15 \mathrm{~m} / \mathrm{s}$, its most frequent values being up to $10 \mathrm{~m} / \mathrm{s}$.

\subsection{Ratio of Wind Speeds}

Knowing the wind speeds at heights of $30 \mathrm{~m}$ and $100 \mathrm{~m}$ above sea level on the FINO 3 platform, Figures 13-15 represent the relationships of the averages of the wind speeds and their standard errors, measured $(\mathrm{m})$ and predicted $(\mathrm{p})$ at $100 \mathrm{~m}$, between 3 and $25 \mathrm{~m} / \mathrm{s}$, where the modeling of the wind potential in the open sea is justified and compared. The data have been grouped for different types of atmospheric stability, in Figures 13a, 14a and 15a, neutral, and in Figures 13b, 14b and 15b, unstable and stable. In the years of study, for neutral stratification, the largest deviations occur between 3 and $9 \mathrm{~m} / \mathrm{s}$ of the measured wind speed, for unstable stratification, the deviations are less than $5 \%$, and for stable stratification, the largest deviations can be punctually up to the $15 \%$ for different measured wind speeds.

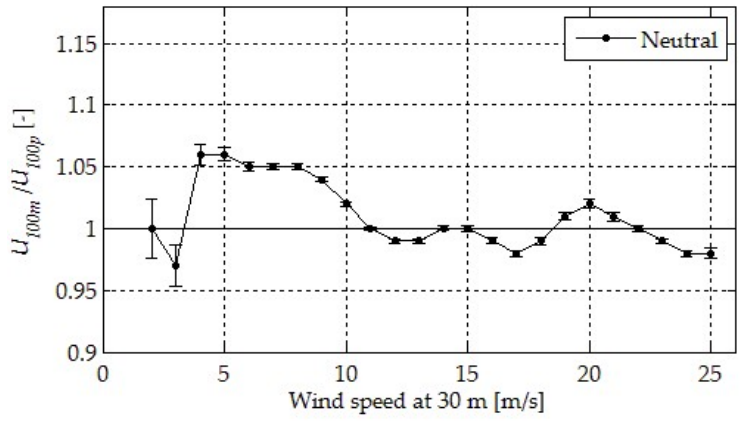

(a)

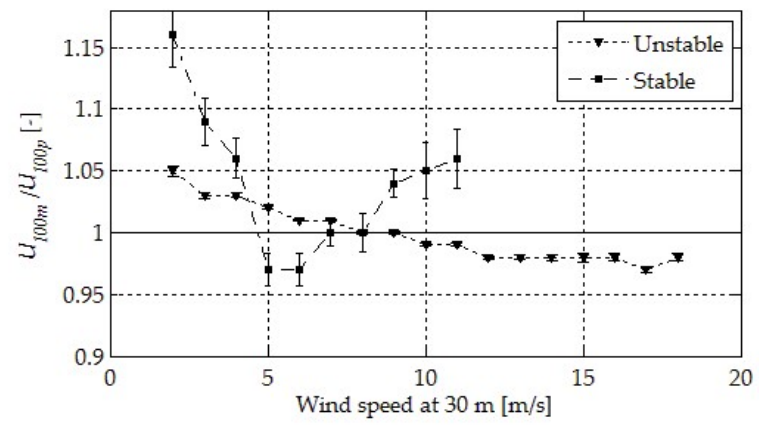

(b)

Figure 13. Bin-averaged ratio of measured and predicted to $100 \mathrm{~m}$ in 2016. 


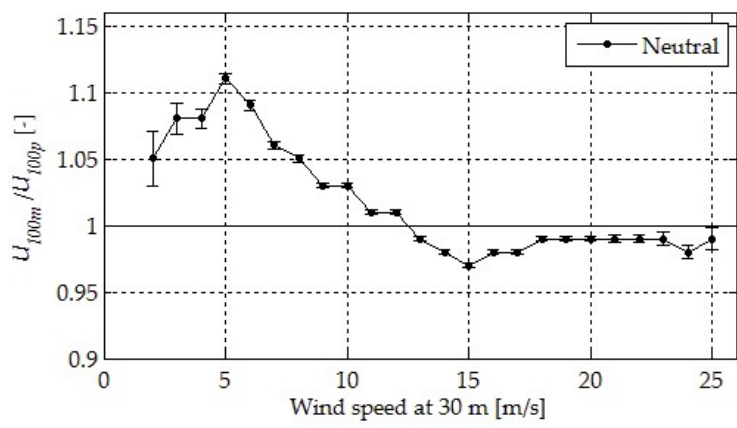

(a)

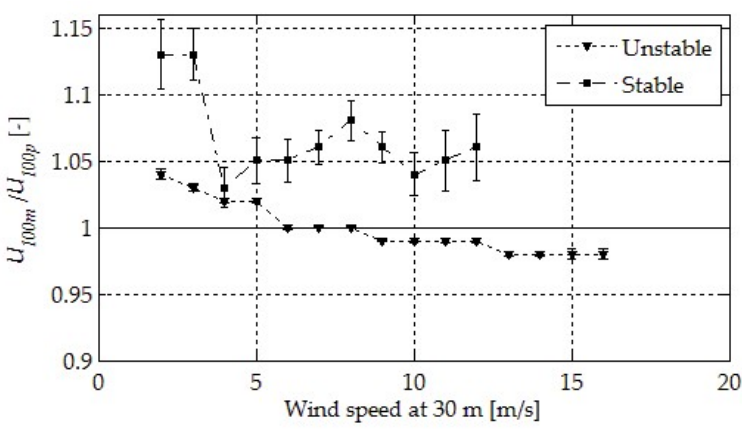

(b)

Figure 14. Bin-averaged ratio of measured and predicted to $100 \mathrm{~m}$ in 2017.

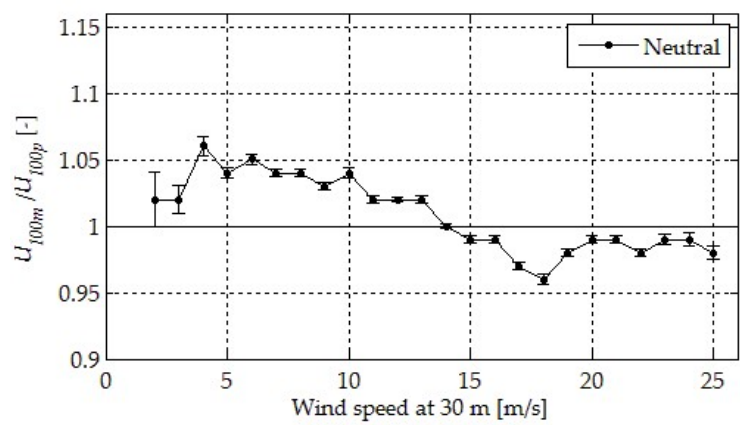

(a)

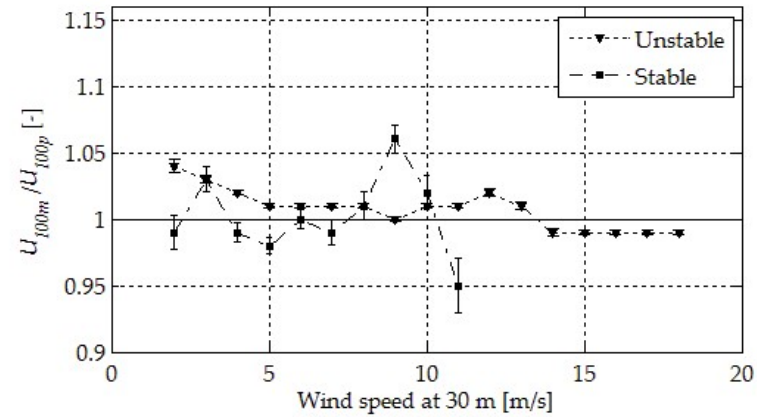

(b)

Figure 15. Bin-averaged ratio of measured and predicted to $100 \mathrm{~m}$ in 2018.

Thus, with neutral stratification, in homogeneous and stationary wind conditions, Equation (2) of the M-O similarity theory adequately models the variation in wind speed with height. The largest deviations between the predicted value and the measured values occur for low wind speeds. On the other hand, for unstable stratification conditions, in Equation (4), with the Paulson stability function, the predicted data of wind speeds are similar to the measured data. This type of stratification is frequent in this location in an annual period. While for stable stratification conditions, Equation (4), with the BusingerDyer stability function, presents the largest deviations between the model and the measured values; however, this type of stratification is rare at the site of study.

\subsection{Energy Production}

The known wind speeds, measured and modeled at $100 \mathrm{~m}$, to calculate the energy production, the power curves, and the power coefficient of the Siemens-Gamesa SWT6.0 MW-154 marine wind turbine were selected, as represented in Figure 16 for an air density of $1.225 \mathrm{~kg} / \mathrm{m}^{3}$. In this wind turbine, with the hub at $100 \mathrm{~m}$ above sea level, the starting speed is $3 \mathrm{~m} / \mathrm{s}$, the nominal speed is $14 \mathrm{~m} / \mathrm{s}$, and the cutting speed is $25 \mathrm{~m} / \mathrm{s}$.

To approximate the integration of the energy calculation to discrete sums, the wind speeds between two integers of the characteristic curves were discretized into twenty values.

Table 3 shows the energy production of said wind turbine in relative terms according to the efficiency of the data cited in each year, which indicate that the real energy that a wind turbine would produce in said location would be higher. 


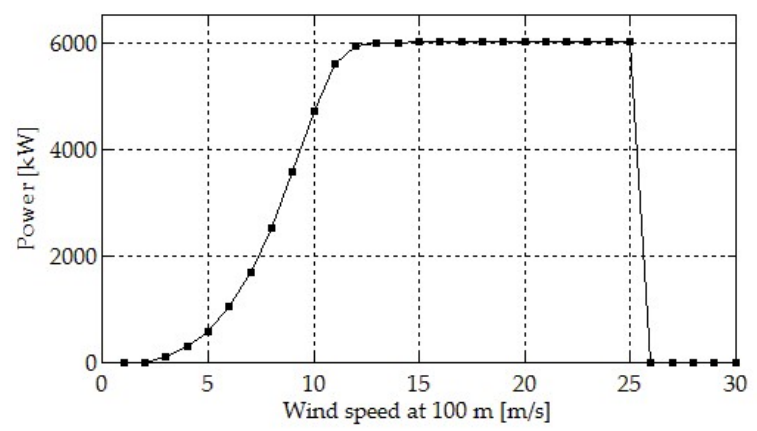

(a)

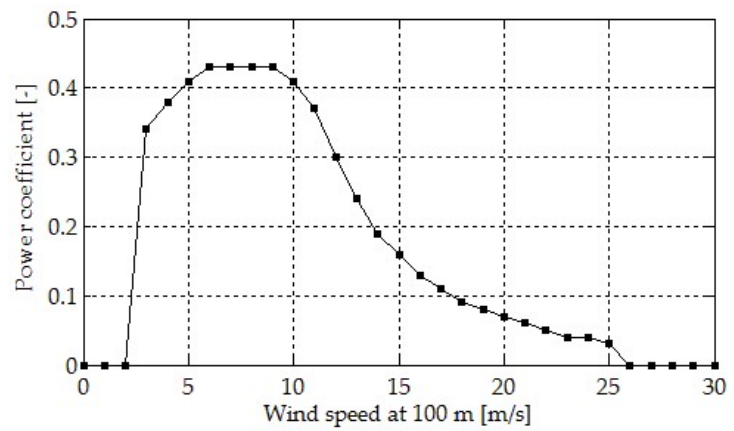

(b)

Figure 16. Wind turbine characteristic curves SWT-6.0 MW-154.

Table 3. Annual energy production of the wind turbine SWT-6,0 MW-154.

\begin{tabular}{|c|c|c|c|c|}
\hline \multirow{2}{*}{ Year } & \multicolumn{2}{|c|}{$\begin{array}{l}\text { Energy in the Rotor with } U(z) \text { Predicted to } 100 \mathrm{~m} \\
(\mathrm{kWh} / \mathrm{y})\end{array}$} & \multirow{2}{*}{$\begin{array}{l}\text { Useful Energy with } U(z) \\
\text { Predicted to } 100 \mathrm{~m}(\mathrm{kWh} / \mathrm{y})\end{array}$} & \multirow{2}{*}{$\begin{array}{l}\text { Useful Energy with } U(z) \\
\text { Measured to } 100 \mathrm{~m}(\mathrm{kWh} / \mathrm{y})\end{array}$} \\
\hline & Input & Output & & \\
\hline 2016 & $106,053,334$ & $23,364,724$ & $23,243,654$ & $23,715,902$ \\
\hline 2017 & $125,968,978$ & $26,311,410$ & $26,146,737$ & $26,801,630$ \\
\hline 2018 & $106,507,350$ & $21,665,150$ & $21,535,364$ & $21,884,986$ \\
\hline
\end{tabular}

The wind speed at $100 \mathrm{~m}$ predicted by the method produces the input energy, or available, $E_{d, \text { annual }}$, in the wind turbine rotor, given by Equation (18). After passing through the rotor, the wind speed slows down and the rotor output energy, or harnessed energy, $E_{a, \text { annual }}$, is given by Equation (19). The last two columns show the useful energy, $E_{u, \text { annual }}$, produced by the wind turbine by applying Equation (20),with the values of the wind speed at $100 \mathrm{~m}$ predicted by the method and measured at the site. The results obtained show that the useful energies for each year are similar, verifying the validity of the proposed method.

Table 4 shows the equivalent operating parameters, $C F$ and $U T$, of said wind turbine, for the wind speeds at the hub height measured on the FINO 3 platform and obtained by the method, in the years of the study, where the relative deviations do not exceed $2.5 \%$.

Table 4. Operating parameters and deviations.

\begin{tabular}{|c|c|c|c|c|c|c|c|}
\hline \multirow[b]{2}{*}{ Year } & \multirow[b]{2}{*}{$\begin{array}{c}\text { Efficacy } \\
\text { Data }\end{array}$} & \multicolumn{2}{|c|}{ Measurement Data } & \multicolumn{2}{|c|}{ Prediction Data } & \multicolumn{2}{|c|}{ Deviations } \\
\hline & & $\begin{array}{c}C F_{m} \\
(-)\end{array}$ & $\begin{array}{l}U T_{m} \\
(\mathrm{~h} / \mathrm{y})\end{array}$ & $\begin{array}{c}C F_{p} \\
(-)\end{array}$ & $\begin{array}{l}U T_{p} \\
(\mathrm{~h} / \mathrm{y})\end{array}$ & $\begin{array}{c}U T_{m}-U T_{p} \\
(\mathrm{~h} / \mathrm{y})\end{array}$ & $\underset{(\%)}{1-U T_{p} / U T_{m}}$ \\
\hline 2016 & 0.823 & 0.450 & 3953 & 0.441 & 3874 & 79 & 1.99 \\
\hline 2017 & 0.881 & 0.510 & 4467 & 0.497 & 4358 & 109 & 2.44 \\
\hline 2018 & 0.763 & 0.416 & 3648 & 0.410 & 3589 & 59 & 1.61 \\
\hline
\end{tabular}

\section{Discussion}

Due to the difficulties in measuring the height of meteorological data in marine conditions, a model was proposed to determine the variation in wind speed with height from meteorological data measured at levels close to the sea surface, for its application to the energy production of the wind turbines to be installed in new offshore wind farms.

The information obtained from the German FINO 3 research platform was of great importance to carry out our study, since it has meteorological data at different heights and oceanographic data, with high efficiency, which allows comparing wind speeds measured and predicted by the method at the height of the hub of a commercial wind turbine, which in our case was $100 \mathrm{~m}$ above sea level.

The modeling of the exposed wind potential is based on the equations of the quantity of motion of the M-O similarity theory for neutral conditions, Equation (2), and non-neutral conditions, Equation (4), being said conditions determined by the bulk Richardson number. 
The greatest difficulty arose in the calculation of the friction speed as it was present both in the equations of the aerodynamic roughness length and in the Obukhov length, being solved by means of the numerical calculation of iteration of the fixed point.

\section{Conclusions}

Wind speed depends on the type of atmospheric stratification, Figures $5-10$. In this way, when the stratification is neutral, all wind speeds were measured up to $25 \mathrm{~m} / \mathrm{s}$ and higher, when it is unstable the most frequent values were up to $15 \mathrm{~m} / \mathrm{s}$, and when it is stable up to $10 \mathrm{~m} / \mathrm{s}$.

The roughness length of the sea surface is a characteristic parameter of Equations (2) and (4), of a variable nature, and with reduced values; thus, for the most extreme conditions of the measured wind speeds, values were obtained slightly greater than $1 \mathrm{~mm}$.

It is usually considered that in open sea conditions the atmospheric stratification is mainly neutral [33], but in the results presented it can be observed that the unstable stratification follows it very closely, so we can infer that the atmospheric stratification in an annual period can be a characteristic of the site that influences the wind potential.

Wind speeds at $100 \mathrm{~m}$ above sea level, measured on the platform and obtained by the method, were applied to the calculation of the energy of the SWT-6.0 MW-154 wind turbine presenting acceptable deviations, so they are considered satisfactory for an industrial application.

The proposed modeling can be extended to study the energy viability of new offshore wind farms based on in situ measurements during the research phase of the project, where the heights of the meteorological measurements are lower than the height of the hub of the wind turbine that will occupy the site.

Author Contributions: Conceptualization, M.I.B.G. and S.P.L.; methodology, M.I.B.G. and M.R.S.H.; software, M.I.B.G.; validation, M.I.B.G., J.M.M. and C.R.G.; formal analysis, M.I.B.G. and M.R.S.H.; investigation, M.I.B.G. and S.P.L.; resources, M.I.B.G.; data curation, M.I.B.G.; writing-original draft preparation, M.I.B.G. and J.M.M.; writing-review and editing, M.I.B.G. and C.R.G.; supervision, M.I.B.G. and S.P.L. All authors have read and agreed to the published version of the manuscript.

Funding: This research received no external funding.

Institutional Review Board Statement: Not applicable.

Informed Consent Statement: Not applicable.

Data Availability Statement: The data are contained within the article.

Acknowledgments: To the Bundesministerium für Wirtschaft und Energie (BMWi) and Projektträger Jülich (PTJ), both of the Government of Germany, for facilitating the use of data of the FINO Project. To Siemens Gamesa Renewable Energy, for the use of the characteristic curves of the SWT-6.0-154 wind turbine.

Conflicts of Interest: The authors declare no conflict of interest.

\section{Nomenclature}

$\begin{array}{lll}C_{H} & \text { Coefficient of main transfer of sensible heat } & (-) \\ C_{P} & \text { Power coefficient } & (-) \\ C F & \text { Capacity Factor } & (-) \\ E_{a, \text { annual }} & \text { Effective energy in the rotor of a wind turbine } & (\mathrm{Wh} / \mathrm{y}) \\ E_{d, \text { annual }} & \text { Available energy in the rotor of a wind turbine } & (\mathrm{Wh} / \mathrm{y}) \\ E_{u, \text { annual }} & \text { Useful energy of a wind turbine } & (\mathrm{Wh} / \mathrm{y}) \\ F_{H s} & \text { Heat kinematic flux } & (\mathrm{K} \mathrm{m} / \mathrm{s}) \\ g & \text { Acceleration due to gravity } & \left(\mathrm{m} / \mathrm{s}^{2}\right) \\ g / \bar{\theta}_{v} & \text { Buoyancy } & \left(\mathrm{m} / \mathrm{s}^{2} \mathrm{~K}\right) \\ h & \text { height to the hub of a wind turbine } & (\mathrm{m}) \\ k & \text { Von Kármán constant } & (-) \\ L & \text { Obukhov length } & (\mathrm{m}) \\ P & \text { Power } & (\mathrm{W})\end{array}$




\begin{tabular}{|c|c|c|}
\hline$P_{a}$ & Air pressure & $(\mathrm{Pa})$ \\
\hline$P_{n}$ & Rated power & $(\mathrm{W})$ \\
\hline$P_{0}$ & Reference pressure & $(\mathrm{Pa})$ \\
\hline$r$ & Mixing ratio & $(-)$ \\
\hline$R i$ & Richardson number & $(-)$ \\
\hline$R i_{b}$ & Bulk Richardson number & $(-)$ \\
\hline$T$ & Time & (h) \\
\hline$T_{a}$ & Air temperature & $(\mathrm{K})$ \\
\hline$T_{S}$ & Water temperature on the sea surface & $(\mathrm{K})$ \\
\hline$u_{*}$ & Friction velocity & $(\mathrm{m} / \mathrm{s})$ \\
\hline$u_{*}^{2}$ & Kinematic tension & $\left(\mathrm{m}^{2} / \mathrm{s}^{2}\right)$ \\
\hline$U$ & Wind speed as a function of height & $(\mathrm{m} / \mathrm{s})$ \\
\hline$U_{h u b}$ & Wind speed for hub height & $(\mathrm{m} / \mathrm{s})$ \\
\hline$U_{h}$ & Wind speed for hub height & $(\mathrm{m} / \mathrm{s})$ \\
\hline UT & Usage Time & $(\mathrm{h} / \mathrm{y})$ \\
\hline$\dot{W}$ & Power of the incident wind on the turbine rotor & $(\mathrm{W})$ \\
\hline$z$ & Height above mean sea level & $(\mathrm{m})$ \\
\hline$z_{0}$ & Aerodynamic roughness length & $(\mathrm{m})$ \\
\hline \multicolumn{3}{|c|}{ Greek Letters } \\
\hline$\alpha$ & Power law parameter & $(-)$ \\
\hline$\alpha_{c}$ & Charnock parameter & $(-)$ \\
\hline$\theta$ & Potential temperature & $(\mathrm{K})$ \\
\hline $\bar{\theta}_{v}$ & Average virtual potential temperature & $(\mathrm{K})$ \\
\hline$\rho$ & Air density & $\left(\mathrm{kg} / \mathrm{m}^{3}\right)$ \\
\hline$\tau$ & Surface tension & $(\mathrm{Pa})$ \\
\hline$v$ & Kinematic molecular viscosity & $\left(\mathrm{m}^{2} / \mathrm{s}\right)$ \\
\hline$\Psi_{M}(z / L)$ & Stability function & $(-)$ \\
\hline \multicolumn{3}{|c|}{ Abbreviations } \\
\hline $\mathrm{BSH}$ & Bundesamt für Seeschifffahrt und Hydrographie & \\
\hline DNV & Det Norske Veritas & \\
\hline GL & Germanischer Lloyd & \\
\hline GWEC & Global Wind Energy Council & \\
\hline IEC & International Electrotechnical Commission & \\
\hline MABL & Marine Atmospheric Boundary Layer & \\
\hline NWP & Normal Wind Profile & \\
\hline $\mathrm{WMO}$ & World Meteorological Organization & \\
\hline
\end{tabular}

\section{References}

1. Global Wind Energy Council (GWEC). Global Wind Report 2021; GWEC: Brussels, Belgium, 2021.

2. World Meteorological Organization (WMO). Guide to Instruments and Methods of Observation. Volume I-Measurement of Meteorological Variables, 2018 ed.; WMO No. 8; World Meteorological Organization (WMO): Geneva, Switzerland, 2018.

3. Stull, R.B. An Introduction to Boundary Layer Meteorology; Springer: Vancouver, BC, Canada, 2009; pp. $347-386$.

4. Barthelmie, R.J.; Sempreviva, S.; Pryor, S.C. The influence of humidity fluxes on offshore wind speed profiles. Ann. Geophys. 2010, 28, 1043-1052. [CrossRef]

5. Csanady, G.T. Air-Sea Interaction: Laws and Mechanisms; Cambridge University Press: Cambridge, UK, 2004 ; pp. 9-15.

6. Kalvig, S.; Gudmestad, O.T.; Winther, N. Exploring the gap between 'best knowledge' and 'best practice' in boundary layer meteorology for offshore wind energy. Wind Energy 2014, 17, 161-171. [CrossRef]

7. International Electrotechnical Commission (IEC). Wind Turbines-Part 3: Design Requirements for Offshore Wind Turbines; IEC 61400-3; International Electrotechnical Commission: Geneva, Switzerland, 2009.

8. Newman, J.F.; Klein, P.M. The impacts of atmospheric stability on the accuracy of wind speed extrapolation methods. Resources 2014, 3, 81-105. [CrossRef]

9. Monin, A.S.; Obukhov, A.M. Basic laws of turbulent mixing in the surface layer of the atmosphere. Geophis. Inst. Acad. Sci. USSR 1954, 24, 163-187.

10. Obukhov, A.M. Turbulence in an atmosphere with a non-uniform temperature. Geophis. Inst. Acad. Sci. USSR 1946, 1, 95-115. [CrossRef] 
11. Wallace, J.M.; Hobbs, P.V. Atmospheric Science: An Introductory Survey, 2nd ed.; Academic Press Publications: Cambridge, MA, USA, 2006; pp. 387-391.

12. Bahamonde, M.I.; Litrán, S.P. Study of the energy production of a wind turbine in the open sea considering the continuous variations of the atmospheric stability and the sea surface roughness. Renew. Energy 2019, 135, 163-175. [CrossRef]

13. Paulson, C.A. The mathematical representation of wind speed and temperature profiles in the unstable atmospheric surface layer. J. Appl. Meteorol. 1970, 9, 857-861. [CrossRef]

14. Businger, J.A.; Wyngaard, J.C.; Izumi, Y.; Bradley, E.F. Flux-profile relationships in the atmospheric surface layer. J. Atmos. Sci. 1971, 28, 181-189. [CrossRef]

15. Dyer, A.J. A review of flux-profile relationships. Boundary-Layer Meteorol. 1974, 7, 363-372. [CrossRef]

16. Garratt, J.R. The Atmospheric Boundary Layer; Cambridge University Press: Cambridge, UK, 1992; pp. 40-62.

17. Smith, S.D. Coefficients for sea surface wind stress, heat flux, and wind profiles as a function of wind speed and temperature. J. Geophys. Res. 1988, 93, 15467-15472. [CrossRef]

18. Charnock, H. Wind stress on a water surface. Q. J. R. Meteorol. Soc. 1955, 81, 639-640. [CrossRef]

19. Petersen, E.L.; Mortensen, N.G.; Landberg, L.; Hojstrup, J.; Frank, H.P. Wind power meteorology. Part II: Siting and Models. Wind Energy 1998, 1, 55-72. [CrossRef]

20. Motta, M.; Barthelmie, R.J.; Vølund, P. The influence of non-logarithmic wind speed profiles on potential power output at Danish offshore sites. Wind. Energy 2005, 8, 219-236. [CrossRef]

21. International Electrotechnical Commission (IEC). Wind Turbines-Part 1: Design Requirements Wind Turbines; IEC 61400-1; International Electrotechnical Commission: Geneva, Switzerland, 2005.

22. Germanisher Lloyds. Guideline for the Certification of Offshore Wind Turbines; Germanisher Lloyds: Hamburg, Germany, 2012.

23. Det Norske Veritas. Design of Offshore Wind Turbine Structures; DNV-OS-J101; Det Norske Veritas: Barium, Norway, 2013.

24. Lange, B.; Larsen, S.; Højstrup, J.; Barthelmie, R.J. Importance of thermal effects and sea surface roughness for offshore wind resource assessment. J. Wind. Eng. Ind. Aerodyn. 2004, 92, 959-988. [CrossRef]

25. Högström, U.; Smedman, A.S.; Bergström, H. Calculation of wind speed variation with height over the sea. Wind Eng. 2006, 30, 269-286. [CrossRef]

26. FINO Datenbank. Available online: https://www.fino-offshore.de/de/index.html (accessed on 20 January 2021).

27. Grachev, A.A.; Fairall, C.W. Dependence of the Monin-Obukhov stability parameter on the bulk Richardson number over the ocean. J. Appl. Meteorol. 1997, 36, 406-414. [CrossRef]

28. Sanz, J.; Cantero, E.; García, B.; Borbón, F.; Irigoyen, U.; Lozano, S.; Hernandes, P.M.; Chávez, R.A. Atmospheric stability assessment for the characterization of offshore wind conditions. J. Phys. Conf. Ser. 2015, 625, 012044.

29. Ebuchi, N.; Toba, Y.; Kawamura, H. Statistical study on the local equilibrium between wind and wind waves by using data from ocean data buoy stations. J. Oceanogr. 1992, 48, 77-92. [CrossRef]

30. Hau, E. Wind Turbines: Fundamental, Technologies, Application, Economics, 2nd ed.; Springer: Berlin, Germany, 2006 ; pp. 528-531.

31. Ashrafi, K.; Hoshyaripour, G. A model to determine the atmospheric stability and its correlation with CO concentration. Int. J. Civ. Environ. Eng. 2008, 2, 82-88.

32. Woodward, J.L. Appendix A: Atmospheric stability classification schemes. In Estimating the Flammable Mass of a Vapor Cloud; American Institute of Chemical Engineers: New York, NY, USA, 1998; pp. 209-212.

33. Businger, J.A. The Marine Boundary Layer, from Air-Sea Interfase to Inversion; Technical note 252; National Center for Atmospheric Research: Boulder, CO, USA, 1985; pp. 60-61. 